\title{
CIDADE, MEMÓRIA E LITERATURA NA INFÂNCIA BERLINENSE DE WALTER BENJAMIN
}

Raquel Imanishi ${ }^{1}$

\section{Resumo}

W. Benjamin escreveu a Infância berlinense entre 1932 e 1938. Sobre essa coleção de reminiscências em miniatura diz um dos biógrafos do filósofo não se tratar de um olhar nostálgico para a vida vivida, mas antes da "tentativa de pôr ante os olhos, através da escrita, a constelação alterada de relações políticas, sociais e culturais de toda uma vida”. Apreensão moderna e contraditória de um passado sem volta, o livro talvez possa ser lido como vestígio de uma história de que se tem pouca notícia. Nascido em 1892 em BerlimCharlottemburg, Benjamin não só cresceu numa cidade que se transformava, mas numa nação unificada pelo alto, na qual prosperava uma "vontade de potência" imperialista. É a esse tempo cheio de mudanças e promessas, que termina em 1914, que Benjamin recorre na aurora de uma segunda catástrofe, a qual não sobreviveria. A leitura de um misterioso fragmento desse livro pretende retomar os nexos entre cidade, memória e literatura.

Palavras-chave: Walter Benjamin, Infância, Panorama, Memória, Cidade

la forme d'une ville Change plus vite, helàs! que le coeur d'un mortel Charles Baudelaire ${ }^{2}$

I.

Infância em Berlim por volta de 1900 foi o nome dado por Walter Benjamin a um conjunto de textos curtos (de número variável nas três edições existentes) composto entre 1932 e 1938 que, a despeito de seu empenho reiterado, não viu editado em vida ${ }^{3}$. Ao que se sabe, sua redação foi iniciada na esteira de um dos mais importantes escritos autobiográficos de seu legado, a Crônica berlinense, redigido por sugestão da revista $\mathrm{O}$ mundo literário, e também só publicado postumamente. Como se lê ali, haviam lhe pedido uma série de glosas em "forma frouxa e subjetiva" sobre "tudo que lhe parecesse digno de nota" no dia-adia da cidade".

\footnotetext{
${ }^{1}$ Departamento de Filosofia, FFLCH-USP.

2 "A forma de uma cidade/Transforma-se mais rapidamente que o coração de um mortal", O Cisne, Les Fleurs du Mal.

3 A primeira edição do livro foi organizada por Theodor Adorno em 1950 com base em diferentes manuscritos e publicações parciais de um ou outro fragmento, sendo republicada nos Escritos em dois volumes, de 1955, e como número 2 da "Bibliothek Suhrkamp", em 1962. A segunda, de 1972, ficou a cargo de Tillman Rexroth, editor do volume IV das Obras completas (Gesammelte Schriften), compreendendo a revisão da edição anterior e acréscimo de fragmentos não incorporados por essa; a terceira, por fim, identificada significativamente como "última versão", foi publicada em 1987 graças à série de manuscritos encontrados em 1981 na Bibliothèque Nationale em Paris, dentre os quais figurava uma versão batida à máquina da Infância berlinense - ao que tudo indica, finalizada em 1938. Segundo o editor da última, Rolf Tiedemann, Benjamin teria "finalizado" a edição do livro no mínimo três vezes, enviando-o a diferentes editores ou com vistas a fazê-lo: a primeira em 1933, a segunda em 1934 e uma última em 1938, quando relata a Gretel Adorno em carta ter retrabalhado pormenorizadamente o conjunto dos fragmentos. Cf. a propósito Gesammelte Schriften, vol. IV-2, Suhrkamp: Frankfurt, pp. 964-972, e Berliner Kindheit um neunzehnhundert - Fassung letzter Hand, Suhrkamp: Frankfurt, $\sigma^{a}$ edição, 1994, pp.111-117. As duas versões em português existentes, de José Carlos Martins Barbosa (Obras Escolbidas, vol. II, Brasiliense: São Paulo, 1987) e de Cláudia de Miranda Rodrigues (Rua de Sentido Único e Infância em Berlim por volta de 1900, Relógio D'Água Editores, 1992) parecem ter por base a segunda edição mencionada, privada entretanto de suas notas.

4 Ainda que o nexo entre a Crônica e a encomenda da revista seja mencionado de forma vaga, sabe-se por seus editores que em outubro de 1931 Benjamin assinou um contrato com O mundo literário - uma das mais
} 
Gershom Scholem, amigo de vida inteira do escritor e o primeiro a ter notícia das notas, foi também quem primeiro chamou a atenção para a mutação sofrida pela Crônica ao desaguar na Infância berlinense. Ainda que a primeira seja o "embrião" a partir do qual a segunda será redigida, escreve ele em seu posfácio, Benjamin decidiu após sua redação não apenas se limitar ao período da infância, mas a fazê-lo de forma "poética e literária". Quando começa a reformular as anotações no outono de 1932, "elimina todos aqueles elementos que remetem diretamente a sua biografia real". Na metamorfose sofrida pelo texto, Scholem destaca o desaparecimento de inúmeras referências às convicções socialistas e à luta de classes presentes nos apontamentos iniciais - "a luz que recai sobre a versão tardia", comenta ele, "é bem mais suave e, com toda agudeza de detalhe, francamente mais conciliadora" que a que inspirara a primeira redação. Conhecendo de perto não só o autor, mas o contexto no qual a obra fora redigida, o amigo conclui: "como uma transformação interna em suas convicções combativas não pode ter ocorrido nesse período - sendo mais provável elas terem se acirrado - o motivo dessa transformação deve ser buscado em circunstâncias externas, ou seja, na distinta intenção literária da nova versão"6.

O preço pago pela fatura poética dos fragmentos finalizados em 1938 seria, assim, não só o abandono dos dados biográficos imediatos, mas da postura de combate assumida de modo decidido a partir do final dos anos 1920. Se no olhar que se volta à cidade natal parece não mais brilhar a lâmina revolucionária que atravessava os textos do autor desde Rua de mão única, tal opacidade deveria ser buscada, não na debilidade de sua chama interna, mas no filtro escolhido como seu anteparo. O ponto de fuga dessa avaliação, ao que tudo indica, era a aparente disparidade entre o teor endiabrado do pensamento benjaminiano e a sobriedade bem comportada das "memórias de infância".

Sem negar validade à observação de Scholem, esse trabalho busca expor duas hipóteses que caminham para uma conclusão contrária à sua: primeiro, a de que a forma literária escolhida para o livro reforça, antes de atenuar, os dados e comentários pessoais expostos na Crônica, na medida em que persegue um aprofundamento da visão subjetiva ali delineada. Como este não se dá, a nosso ver, no âmbito dos dados referidos, mas no modo como a obra é escrita, a correlação entre o plano biográfico e as transformações em vários âmbitos "descritas" no livro não deve ser buscada em dados isolados, mas em sua configuração e arquitetura interna. A segunda hipótese é a de que a obra busca, justamente por meio dessa composição personalíssima, refletir e condensar uma experiência coletiva: o desenvolvimento contraditório, e mesmo perverso, da metrópole e da cultura modernas e sua configuração particular na antiga capital da Prússia. Para apresentá-las, vamos olhar de perto a fatura de um único texto desse pequeno volume, o que se intitula Kaiserpanorama.

importantes publicações da República de Weimar, para qual escrevia regularmente desde 1925 - no qual se comprometia a entregar a cada três meses, até março de 1932, quatro "crônicas berlinenses com 200 a 300 linhas cada". Cf. "Nachwort" e "Editorisches Postskriptum" in Berliner Chronik, Suhrkamp: Frankfurt, 1" edição revista, 1988, e as notas acerca do manuscrito in Gesammelte Schriften, vol. VI, Suhrkamp: Frankfurt, pp. 631 e 795 e segs. Em Fisionomia da metrópole moderna, Wille Bolle explica o não-cumprimento do contrato pela crise depressiva que, em 1932, quase teria levado Benjamin ao suicídio. Cf. Op. cit. Edusp: São Paulo, 1994, p. 316.

5 "Nachwort", op. citada, p. 94 e Walter Benjamin/Gershom Scholem, Correspondência, Perspectiva: São Paulo, 1993, pp. 32-34.

6 "Nachwort", op. cit, grifos meus. 


\section{Um Panorama da Berlim imperial}

Um dos grandes fascínios das imagens de viagem encontradas no Panorama do Imperador era não importar onde se iniciava a ronda. Como a tela, com os assentos à frente, tinha forma de círculo, cada imagem passava pelo conjunto das paradas, e se via destas, a cada par de orifícios, sua distância esmaecida. Lugar sempre se achava. E, sobretudo, perto do fim da minha infância, quando a moda já voltara as costas aos panoramas imperiais, era comum circular pela sala semivazia.

No Panorama do Imperador não havia música - música que torna tão entorpecentes [erschlaffend] as viagens com o filme. Parecia-me superá-la um pequeno efeito, incômodo, a bem da verdade. Era um toque de campainha, que soava poucos segundos antes da imagem se retirar aos solavancos para dar vez, primeiro, a uma lacuna e, logo, à imagem seguinte. E sempre que ela ressoava, impregnavam-se com a dor da despedida as montanhas até o sopé, as cidades em suas janelas espelhadas, as estações ferroviárias com sua fumaça amarela, os vinhedos até a folha mais ínfima. Me convenci de que era impossível esgotar dessa vez a glória daquele domínio [Herrlichkeit der Gegend]. E então surgiu o propósito, jamais cumprido, de passar ali, uma vez mais, no dia seguinte. Contudo, antes de estar decidido, estremeceu toda a estrutura, da qual me separava apenas um tabique; a imagem vacilou em sua pequena moldura, para fugir em seguida, pela esquerda, das minhas vistas.

As artes que aqui perduraram se extinguiram com o século 20. Quando ele tem início, as crianças eram seu último público. Os mundos distantes não eram sempre estranhos a elas. Ocorria da saudade despertada por eles não evocar o desconhecido, mas o caminho de casa. Assim, quis me persuadir uma tarde frente à transparência da cidadezinha de Aix, que eu já teria brincado outrora no calçamento cuidado pelos velhos plátanos do Cours Mirabeau.

Se chovia, não me demorava do lado de fora, frente à lista das cinqüenta imagens entrava lá dentro e encontrava nos fiordes e sob os coqueiros a mesma luz que, à noite, à hora do dever de casa, iluminava minha escrivaninha. A menos que um defeito na iluminação fizesse, subitamente, com que a paisagem se descorasse. Então, sob seu céu de cinzas, ela permanecia em silêncio; era como se me fosse possível ter ouvido o vento e os sinos se simplesmente tivesse apurado o ouvido. ${ }^{7}$

Esse pequeno texto é o segundo "fragmento" da última versão da Infância, finalizada em 1938. Como o conjunto do livro, em particular nessa versão, sua redação é muito sintética e seu estilo corresponde ao ideal do Benjamin tardio: nas palavras de Rolf Tiedemann, a "exposição sóbria do particular" numa forma concisa e extremamente complexa que, mesmo pagando tributo a Bert Brecht e Johann Peter Hebel, era muito benjaminiana Mesmo que não se saiba, a princípio, qual é exatamente seu objeto, muito menos onde o autor quer chegar com isso, percebe-se já à primeira leitura que não se trata de um relato autobiográfico convencional - a descrição mais ou menos detida de eventos que ocorrem no tempo de uma vida, dentro de uma concatenação lógica ou evolutiva (infânciaadolescência-idade adulta, ou mais simplesmente, presente-passado-futuro). Trata-se de apresentar uma imagem - não uma imagem qualquer, mas uma imagem na qual se sedimentou uma experiência cuja origem história é delimitada, grosso modo, pelo título do livro: "infância em Berlim por volta de 1900".

Em relação a nosso texto, essa delimitação aparentemente vaga fornece a chave para um elemento preciso: seu título. A infância à qual o escritor se volta em 1932, em meio à

\footnotetext{
${ }^{7}$ Berliner Kindheit um neunzehnhundert - Fassung letz̧ter Hand, edição citada, p. 14-15.

${ }^{8}$ Editorisches Postskirptum“ in Berliner Kindheit um neunzebnhundert - Fassung letəter Hand, edição citada, p. 116.
} 
derrocada da República de Weimar e à ascensão do fascismo, é uma infância que transcorre na Berlim do Segundo império, em um tempo de transformações profundas. "Em 1868 os muros que separavam a cidade dos arredores são derrubados, simbolizando a queda dos antigos limites da cidade e sua expansão e transformação. Durante o reinado de Wilhelm I (1871-1888) Berlim se industrializa rápida e constantemente. Seu neto Wilhelm II (reinado de 1888 a 1918), grande entusiasta do progresso técnico, estimula a expansão industrial, fortificando a já poderosa indústria metalúrgica, estimulando o desenvolvimento da indústria química e elétrica, reforçando o já célebre quadro burocrático prussiano"". Na observação de um contemporâneo espirituoso: "Berlim tornou-se uma cidade grande da noite para o dia, como um especulador feliz" ${ }^{\prime 10}$. Nascido em julho de $1892 \mathrm{em}$ Berlin-Charlottenburg ${ }^{11}$, uma região nobre da Grande Berlim que só em 1920 seria incorporada administrativamente ao município, Benjamin não só cresceu numa cidade que se transformava em metrópole, mas numa nação unificada pelo alto na qual prosperava uma "vontade de potência" imperialista. Como se sabe das aulas de história, a unificação da Alemanha sob a liderança da Prússia, que se seguiu às guerras de 1870-1871, abre caminho para uma nova situação geopolítica, na qual o país desponta como potência econômica expansionista. Colocado na abertura do livro, logo depois do auto-retrato "Loggias" ["Varandas", na versão portugue$\mathrm{sa}]^{12}$, o "Panorama do Imperador" não é uma referência qualquer dentre os vários panoramas construídos no século 19 na Europa e no Novo Mundo: é um panorama específico ${ }^{13}$. Inaugurado em 1880 na mais famosa passagem berlinense (chamada também Kaiserpassage), ele foi assim nomeado em homenagem ao imperador Wilhelm $\mathrm{I}^{14}$. Seu proprietário, August Fuhrmann - entusiasta do progresso técnico como o neto que sucede este Imperador no trono - era um ex-combatente da Guerra Franco-Prussiana, além de patriota de carteirinha. Não é casual que nas primeiras versões do texto, Benjamin mencionasse após o soar perturbador da campainha a "magia ilusória" de "oásis com pastorais" e "muralhas em ruínas com marchas fúnebres" ". Entre as séries diletas de Fuhrmann, constavam as obras representativas do novo Império ${ }^{16}$, que reduziam os antigos marcos da cidade a ruínas, e as dedicadas às pompas e monumentos fúnebres. Outra de suas predileções eram as exposições da indústria, nas quais os visitantes eram levados a prestigiar a pujança industrial da cidade e a se convencer das benesses do expansionismo. Para mostrá-las, oásis com pastorais era pouco, não sendo casual que Benjamin mencione, ao fim do texto, "fiordes e coqueiros". Sobre uma exposição realizada no campo de Tempelhof no finalzinho do século, escrevia um dos

\footnotetext{
${ }^{9}$ Leopoldo Waizbort, As aventuras de Georg Simmel. Editora 34: São Paulo, 2000.

10 O comentário, feito numa publicação alemã em 1902, é citado por C.H. Haxthausen, "Eine neue Schönheit. Ernst Ludwig Kirschners Berlinbilder", in T. Steinfeld e H. Suhr (orgs.), In der grossen Stadt. Die Metropole als kulturtheoretische Kategorie, A. Hain: Frankfurt am Main, 1990, p. 77.

${ }^{11}$ Como seu nome indica, antigo burgo da princesa Charlotte.

12 Sobre "Loggien", um texto escrito em julho de 1933, Benjamin comentou a Scholem conter "o mais preciso retrato que poderia ser feito por mim, de mim mesmo", Cf. Gesammelte Briefe, Vol. IV, Suhrkamp: Frankfurt, 1998, p. 267.

13 Sobre a irradiação dos panoramas no final do século 19 na França, nos EUA e mesmo no Brasil, pode-se conferir Vanessa R. Schwartz "O espectador cinematográfico antes do aparato do cinema: o gosto do público pela realidade na Paris fim-de-século" in Leo Charney e V. Schwartz. O cinema e a invenção da vida moderna. Cosac \& Naify: São Paulo, 2001; Flávia Cesarino Costa. O primeiro cinema. Scritta: São Paulo, 1995; e Vicente de Paula Araújo. Salões, circos e cinemas de São Paulo. Perspectiva: São Paulo, 1981.

${ }^{14}$ As informações sobre o Panorama de August Fuhrmann provém de Michael Bienert e Erhard Senf. Berlin wird Metropol - Photographien aus dem Kaiser-Panorama. be.bra-Verlag, 2000.

15 Gesammelte Schriften, IV-1, edição citada, p. 239.

16 Sobre essas obras, cuja pérola da coroa é o novo Parlamento, cf. Godehard Hoffmann, Architektur für die Nation? - Der Reichstag und die Staatsbauten des Deutschen Kaiserreichs 1871-1918. DuMont: Köln, 2000.
} 
mais notórios cronistas da cidade: "vê-se aqui o Oriente em carne e osso: beduínos, dervishes, turcos, gregos (...) dispõe-se aqui incontestavelmente em seu estado original" ".

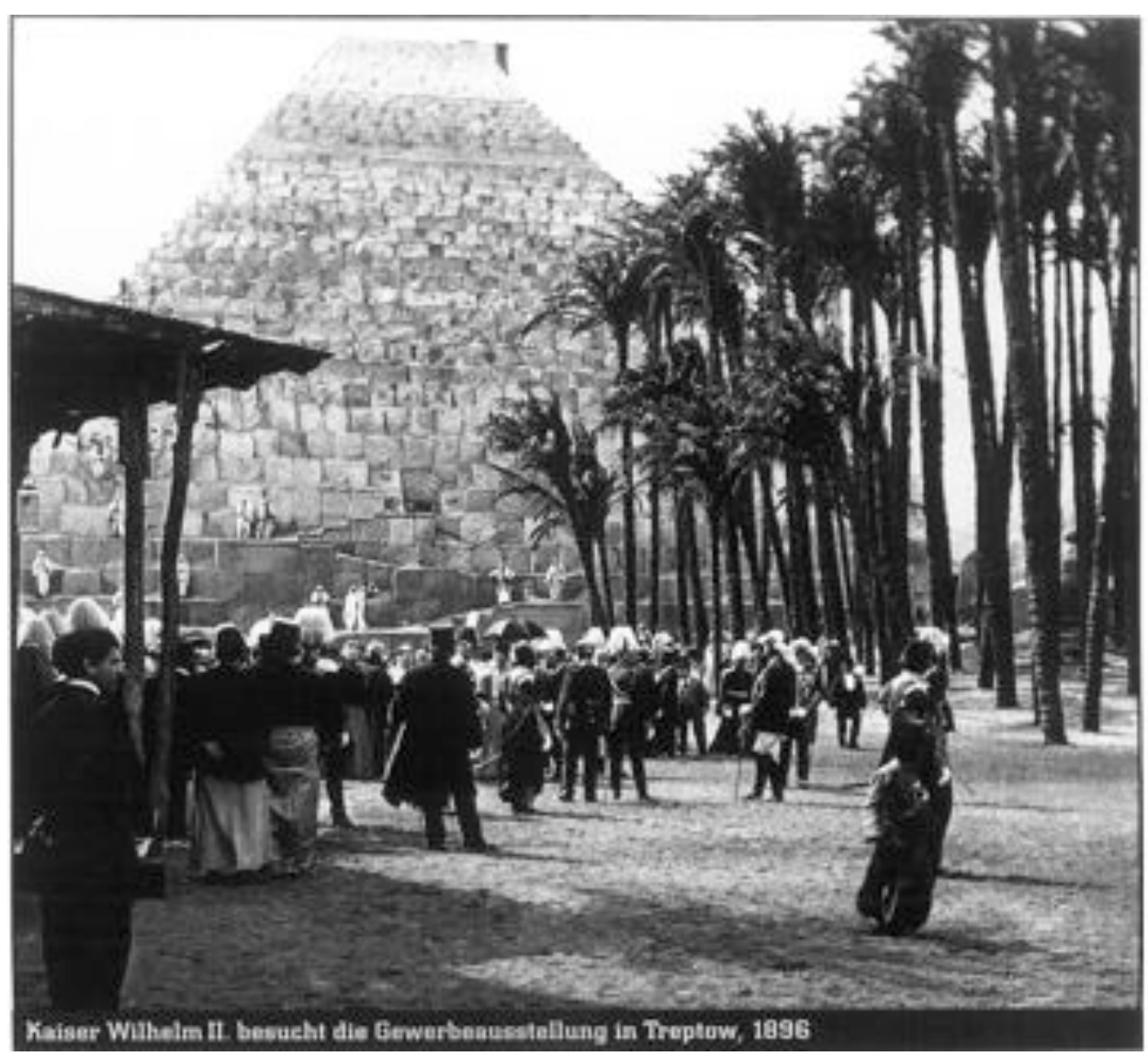

Michael Bienert e Erhard Senf. Berlin wird Metropol - Photographien aus dem Kaiser-Panorama. be.braVerlag, 2000, p.77

Assim, o Kaiserpanorama se precipita na Infância berlinense não apenas como instância significativa das novas formas de entretenimento que nascem nesses períodos, mas como citação de um quadro histórico preciso ${ }^{18}$. Isso explica porque o mesmo título possa ter sido usado, em Rua de mão única, para nomear uma "viagem pela inflação alemã". No livro de 1928, a legenda que acompanhava a escrita da cidade ${ }^{19}$ com esse nome não descrevia um cinematógrafo batizado para honrar Imperadores e seu Império, mas o que se seguira no país como seu resultado. Em lugar da instituição "real" (o Panorama de Fuhrmann), Benjamin apresentava um panorama ético-espiritual da República de Weimar, que terminava com palavras duras: "uma vez degenerada a sociedade, sob desgraça e avidez, a tal ponto que ela só pode ainda receber os dons da natureza pela rapina, que ela arranca os frutos

\footnotetext{
17 Citado por Michael Bienert e Erhard Senf. op. citada, p. 77.

18 Talvez não seja forçar a nota, apontar no próprio vocabulário empregado por Benjamin vestígios dessa referência. Isso poderia ser visto, p. exemplo, na passagem em que se compara o ambiente do Panorama imperial com um espaço de magnificência (ou glória, como traduzi no texto), subitamente descoberto pela criança.

19 Sobre o conceito de escrita da cidade (Bilderschrift), cf. Willi Bolle, "A metrópole como Medium-dereflexão”, in Leituras de Walter Benjamin. Márcio Selligmann-Silva (org.). Annablume/Fapesp: São Paulo, 1999.
} 
imaturos para poder trazê-los vantajosamente ao mercado e que ela tem que esvaziar toda a bandeja somente para ficar saciada, sua terra empobrecerá e o campo trará más colheitas"20.

Bom, pode-se imaginar que escrevendo o livro em 1932, já praticamente no exílio, Benjamin estava recolhendo os frutos dessa colheita amarga, semeada lá atrás nos anos fundadores da sua infância, para fazer deles esse maná inesgotável que é a Infância berlinense. Para tentar entender como ela é construída, voltemos uma vez mais ao texto a fim de esclarecer melhor o segundo elemento do seu título: o panorama.

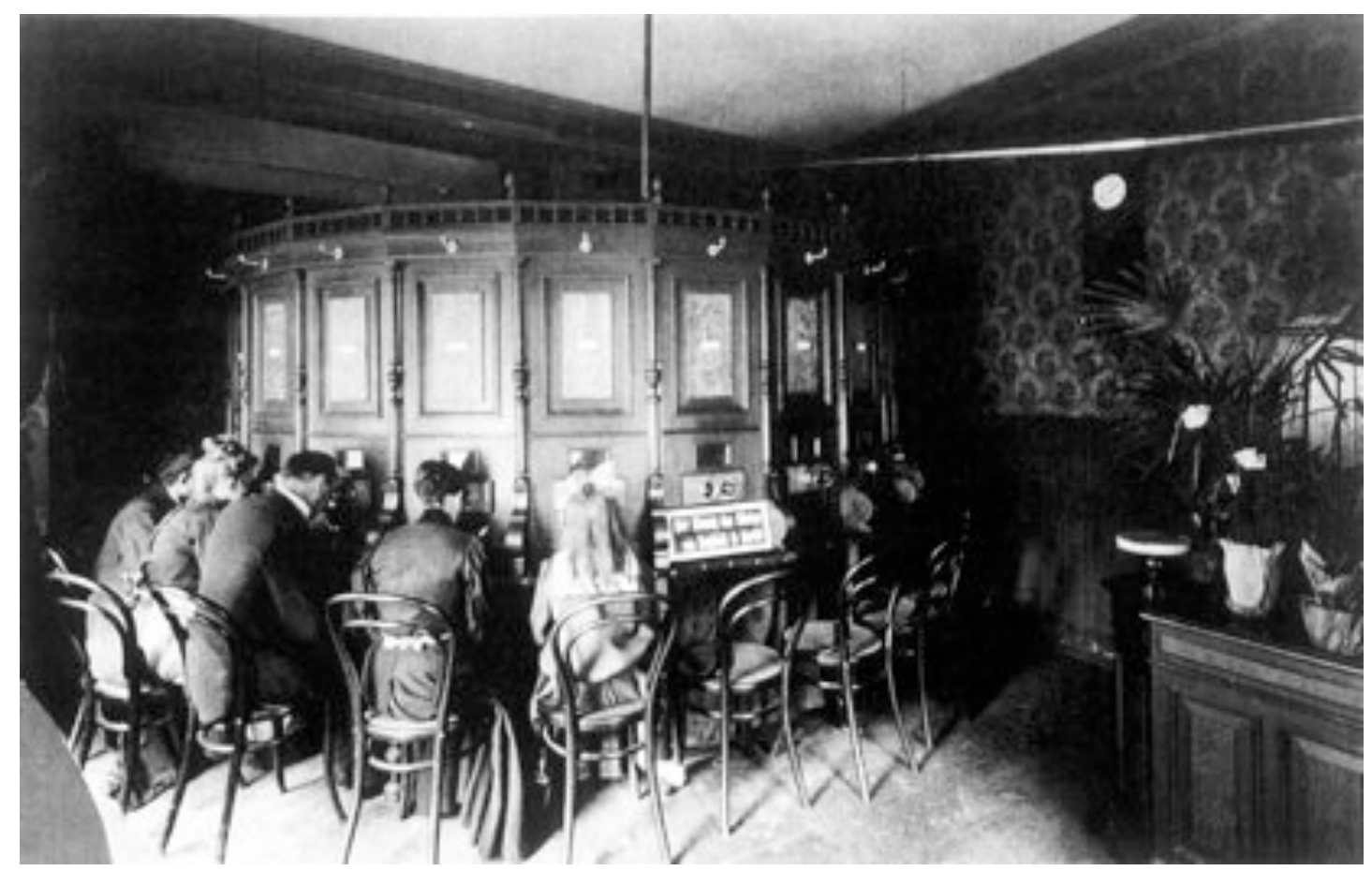

Michael Bienert e Erhard Senf. Berlin wird Metropol - Photographien aus dem Kaiser-Panorama. be.braVerlag, 2000, p.9.

Nos últimos tempos, vários trabalhos têm se dedicado à série de invenções técnicas contemporâneas ou pouco anteriores ao cinema em busca do que seria uma espécie de "pré-história da sensibilidade moderna". Na avaliação de uma destacada estudiosa norteamericana, "os espectadores de cinema levaram para a experiência cinematográfica modos de ver cultivados em uma variedade de atividades e práticas culturais" 21 . No início, diz ela, "os filmes foram considerados simplesmente uma nova técnica para representar o movimento, e não estava claro se seriam suficientes como um entretenimento" ${ }^{22}$. Dessa perspectiva, o cinema não seria o ápice de uma evolução teleológica, na qual a reprodução realista se tornaria cada vez mais precisa e perfeita, mas um elo entre outros dentro de um processo histórico-cultural de longa duração, do qual fariam parte a imprensa popular, os espetáculos ultrarealistas, e mesmo o necrotério - que em Paris, por exemplo, virou um verdadeiro fenômeno cultural no final do século 19. O que se costuma destacar nesse conjunto de práticas é não só a confluência de distintas técnicas de reprodução - desde o desenho e a pintu-

\footnotetext{
20 Obras escolbidas, Vol. II, edição citada, p. 26.

${ }^{21}$ Vanessa Schwartz, op. cit, p. 412.

22 Vanessa Schwartz, op. cit, p. 434.
} 
ra (que compunham inicialmente os panoramas artísticos) até a fotografia ${ }^{23}-$, mas também o gosto do público (e de seus executores) pela "realidade".

Ao que me parece, o interesse das formulações de Benjamin no Kaiserpanorama ${ }^{24}$ é a busca de um pensamento mais complexo e integrado acerca desses marcos, constituídos em um passado, então, recentíssimo. Essa busca começa por pôr em xeque - não por desejo próprio, diga-se de passagem - a distinção inequívoca entre ilusão e realidade. Um dos aspectos mais fascinantes (e assustadores) das novas técnicas de reprodução mecânica parecia ser para ele, àquela altura, justamente a eliminação (aparente) do aspecto construtivo (ou artificioso) da arte. A naturalidade com que, no Panorama do Imperador, se aceitava a aleatoriedade da ordem de imagens - a ponto de não importar "onde se iniciava a ronda" - é distinta, mas de certo modo análoga, à intercambialidade entre lembranças efetivas e lembranças criadas - fazendo com que a sugestão de uma imagem desconhecida pudesse evocar subitamente "o caminho de casa".

Ora, a proximidade entre essas constatações e os experimentos "anarquistas" dos surrealistas, que no início dos anos 1920 haviam começado a explorar as correlações entre sono e vigília, não poderia passar batido a um crítico atento como Benjamin. Num texto escrito poucos anos antes, ele destacara que no início do surrealismo "a vida só parecia digna de se vivida quando se dissolvia a fronteira entre o sono e a vigília (...), e a linguagem só parecia autêntica quando o som e a imagem, a imagem e o som, se interpenetravam, com exatidão automática, de forma tão feliz que não sobrava a mínima fresta para inserir a pequena moeda a que chamamos 'sentido" 25 . Já nesse texto, no entanto, o escritor ressaltava que o potencial político e verdadeiramente revolucionário do movimento se revelara no momento em que seus protagonistas haviam fugido do "fascínio da embriaguez", voltando-se para o que ele nomeava "iluminação profana". Ao esclarecê-la, Benjamin fornecia elementos importantes para entender seu próprio procedimento na Infância berlinense e, em particular no Kaiserpanorama: "Toda investigação séria dos dons e fenômenos ocultos, surrealistas e fantasmagóricos, precisa ter um pressuposto dialético que o espírito romântico não pode aceitar. De nada nos serve a tentativa patética ou fanática de apontar no enigmático o seu lado enigmático; só devassamos o mistério na medida em que o encontramos no cotidiano, graças a uma ótica dialética que vê o cotidiano como impenetrável e o impenetrável como cotidiano". ${ }^{26}$ Extraindo conseqüências práticas dessa reflexão, o autor redige o texto que nos ocupa de olho no fascínio exercido pelas imagens e seu potencial de sonho, mas preocupado principalmente com o momento delicado do despertar. Considerada a hora em que o texto é redigido, que não recomendava o uso de trombetas, a redação do texto é das mais sutis. Sua estratégia maior nesse sentido poderia ser descrita por uma anotação feita, anos depois, para a Obra das passagens: "Há portanto um parentesco estreito entre a recordação e o despertar".

Como nota Dolf Oehler em um belo texto sobre a "poesia da citação" presente nessa obra, Benjamin está “à procura da intensidade do sonho", mas não deseja permane-

\footnotetext{
23 Benjamin nota, nesse sentido, no primeiro Exposé da Obra das passagens que Daguerre foi discípulo do pintor panoramista Prévost.

${ }^{24}$ Sem pretender remontar à gênese das observações reunidas na Obra das passagens, parece interessante pensar que ao retomar em 1934 o trabalho das "Passagens parisienses" (interrompido em 1929), no qual há um caderno específico (Konvolut Q) dedicado aos panoramas, Benjamin já tinha atrás de si a redação desse fragmento.

25 "O surrealismo - o último instantâneo da inteligência européia", trad. Sérgio Paulo Rouanet in Obras escolhidas. Brasiliense: São Paulo, 1994, p. 22.

26 idem, pp. 32-33.
} 
cer em seus domínios ${ }^{27}$. Para que isso seja possível, é necessário encontrar (ou reencontrar) o que escritor chama a certa altura "constelação do despertar". Trata-se de trazer à tona "um saber ainda não consciente do passado", que só pode ser alcançado com uma combinação paradoxal de proximidade e distância. Não é à toa que em nosso texto distintas modalidades de pretérito se alternem sem motivo aparente. O sinal maior desse despertar, no entanto, é a consciência clara do presente. No Panorama Imperial, seu toque é dado pela campainha incômoda que interrompe o fluxo entre imagem e inconsciente, chamando o espectador para descontinuidade entre a realidade criada, que imita uma natureza não mais presente, e o aparato que a cria. Para apreender seu funcionamento, deve-se evocar seu modelo declarado, a obra de Proust.

27 "Ciência e poesia da citação no Trabalho das passagens" in Terrenos vulcânicos. Cosac \& Naify: São Paulo, 2004, p. 246. A citação precedente também vem de Oehler. 